\title{
The epidemiology of common mental disorders in Libya: a systematic review
}

\author{
Mansour Abdulshafea ${ }^{* *}$,, Abdul Hakim Rhouma² Nadeem Gire $^{3}$, Ali AlMadhoob ${ }^{3}$, Usman Arshad ${ }^{4}$ and \\ Nusrat Husain ${ }^{5}$
}

\begin{abstract}
Introduction: There has been a global increase in the prevalence of common mental disorders (CMD), particularly in conflict hotspots. The limited amount of resources is one of the key barriers to effective treatment within Low- and Middle-income countries (LAMICS). The lack of service provision for mental health disorders in LAMICs has resulted in limited opportunities to conduct mental health research. Libya is a North African country that has suffered from ongoing conflict with the current political unrest in Libya further impacting the mental health of the population.

Main text: The aim of this review is to conduct a synthesis of evidence regarding the estimated prevalence and associated risk factors of CMD in Libya. A search was completed in the academic databases; PubMed, Medline, EMBASE, PsychINFO, CINHAL, and the Institute for Development, Research, Advocacy and Applied Care (IDRAAC) from inception to March 2020. Only studies that investigated prevalence and associated risk factors of CMD in Libya were included. A total of 219 studies were identified of which 15 met the inclusion criteria for the review. There were $(n=3)$ papers investigated the prevalence of depression, $(n=4)$ studies were focused on stress-related disorders and the remaining papers looked at both anxiety and depression. Statistically, sample sizes of the included studies ranged from $(n=41-13,031)$ for the prevalence studies (mean $=1188.6$, median $=233$ ).

Conclusion: The status of Libya as a conflict hotspot has led to a reduced level of epidemiological data on mental health, with a vital need to conduct research in CMD. Libya requires better clinical governance which can allow for more scientific research into CMD and enabling the Libyan government to develop evidence-based policy initiatives for CMD.
\end{abstract}

Keywords: Anxiety, Depression, Libya, Mental health, Psychiatric, Prevalence, Risk factors

\section{Introduction}

The prevalence of Common Mental Disorders (CMD) has been increasing globally, with areas in the in-conflict zones, in particular experiencing considerable morbidity and mortality due to CMD $[1,2]$. The limited research and epidemiological data from low resource settings is a major barrier to the delivery of effective treatment approaches within Low- and Middle-Income Countries (LAMICs) [3]. In addition, civil war and political unrest further increases the challenges of carrying out robust

\footnotetext{
*Correspondence: mabdulshafea@gmail.com

1 Singleton Hospital, Sketty Ln, Sketty, Swansea SA2 8QA, UK

Full list of author information is available at the end of the article
}

research [4]. Libya has been fragmented by civil war since February 2011, with limited research data regarding the current situation of CMD within this setting [5].

CMD are one of the leading causes of disability in the global burden of disease [6-8]. CMD includes depressive and anxiety disorders, which make up a significant proportion of morbidity seen within health care services [9]. Morbidity due to CMD has been reported to have a negative impact on wider socioeconomic health outcomes [1]. The prevalence of CMD shows large variations, particularly reported to be higher in LMICs [10] and is significantly more prevalent among women than men and those with comorbid physical illnesses [11]. 
In Libya the political unrest has led to the inadequate availability of health services, particularly mental health services [5, 12]. Lack of resources and health care provision further limits access to evidence-based mental health treatments. In addition, mental health disorders are associated with several risk factors, such as childhood trauma, low socioeconomic status, neglect, stressful life events and other trauma [13-15]. In Libya, the civil war may have caused significant complex trauma and is leading to an increase in the incidence of mental health disorders [5].

Furthermore, in Libya, Okasha and colleagues [16] reported that per 100,000 population, the country has approximately 0.2 psychiatrists, 5 psychologists, 0.05 psychiatric nurses and 1.5 social workers, highlighting the scarcity of trained mental health professionals to meet the needs of the estimated population of 6.73 million $[5,12]$. This coupled with the limited access to psychiatric services both within inpatient and community mental health settings, results in an urgent need for research to bridge this mental health treatment gap [5]. In addition, Libya is a country consisting of mainly remote and rural settings, which requires the strengthening of mental health service provision, by providing broader geographical coverage while still being cost-effective [5]. This includes the integration of mental health care into primary care services which can help reduce the treatment gap within LMICs, such as Libya [17]. A lack of stable healthcare infrastructure, poor clinical governance and limited research capacity strengthening initiatives, is the current situation being experienced in conflict settings, particularly Libya [4]. Therefore, a service user led approach may act as the required building blocks when changing the way mental health care is provided in Libya. Taking into account the limited availability of epidemiological data in Libya, the present systematic review aimed to conduct a synthesis of the available evidence on the estimated prevalence and associated risk factors of CMD in Libya.

\section{Main text}

Aim

The aim of this review is to conduct a synthesis of evidence regarding the estimated prevalence and associated risk factors of CMD in Libya.

\section{Methods}

\section{Search strategy}

A search was conducted on the following databases: PubMed, Medline, EMBASE, PsychINFO, CINHAL and Institute for Development, Research, Advocacy and Applied Care (IDRAAC) from database inception to
March 2020. The search strategy consisted of Medical Subject Headings (MeSH) and search terms related to "Libya", "depression", "anxiety", "psychiatric" and "mental disorders". The use of these specific keywords was adapted from a previous literature review conducted by Mirza and colleagues [18] (See Additional file 1 for full search strategy).

\section{Inclusion and exclusion criteria}

The main variables of interest for the search were the identified prevalence and associated risk factors of CMD in Libya. The systematic review included papers which had a focus on (a) CMD, as outlined in Mirza and colleagues [18] and (b) were conducted within Libya. Studies were excluded if they were published as poster publications, conference abstracts or did not have an outcome which was associated with CMD.

\section{Data synthesis}

On completion of the search the data gathered was extracted from the online databases. First, two reviewers (AR and MA) screened the relevant studies by reviewing the titles and abstracts of the identified papers. In the second stage, the reviewers evaluated and assessed the full manuscripts of all selected papers independently. The reviewers then independently evaluated the study characteristics including first author, year of publication, sample size and setting to determine the suitability of the paper for inclusion. Any disagreements were resolved by senior author $(\mathrm{NH})$.

\section{Use of hand search}

Due to the limited availability of research literature in relation to mental health in Libya [12], we removed all date and language restrictions to ensure a broad search of the available evidence. A hand search was conducted to examine any grey literature that could be obtained either online or by direct contact with identifiable authors. This involved screening the reference lists of all eligible publications for further published reports and citations of unpublished research. Other sources internet search engines (Google, Google Scholar) were also explored for research related to the key words. However, the Google Scholar search was limited to the first 150 most relevant articles. In addition, there were multiple attempts to contact experts in the field from Libya for any unpublished papers.

The search results of the grey literature were then examined against the inclusion criteria of the review. To keep the process both replicable and transparent, the unfiltered search results were saved and retained for future potential re-analysis. However, due to the 
ongoing political unrest, we were not able to contact some experts in the field in Libya for $(n=2)$ articles published in the Jamahiriya Medical Journal. Our grey literature search was unable to retrieve unpublished materials or grey literature.

Overall, a total of $(n=15)$ papers met the inclusion criteria and were included as part of the review which included all original research papers that focused on CMD, primarily anxiety and/or depression in Libya. (See Consort diagram for further details of included/ excluded studies).

\section{Results}

The initial search identified 219 papers, of which fifteen were non-duplicated papers that met the inclusion criteria of the review. A total of fourteen were cross sectional studies and one was a case-control study which is shown in Fig. 1. We did not find any prospective studies on the natural course of CMD or rigorously controlled trials which provided estimates of prevalence data. The sample sizes of the included studies ranged from $(n=41-13,031)$ for prevalence studies $($ mean $=1188.6$, median $=233$ ).
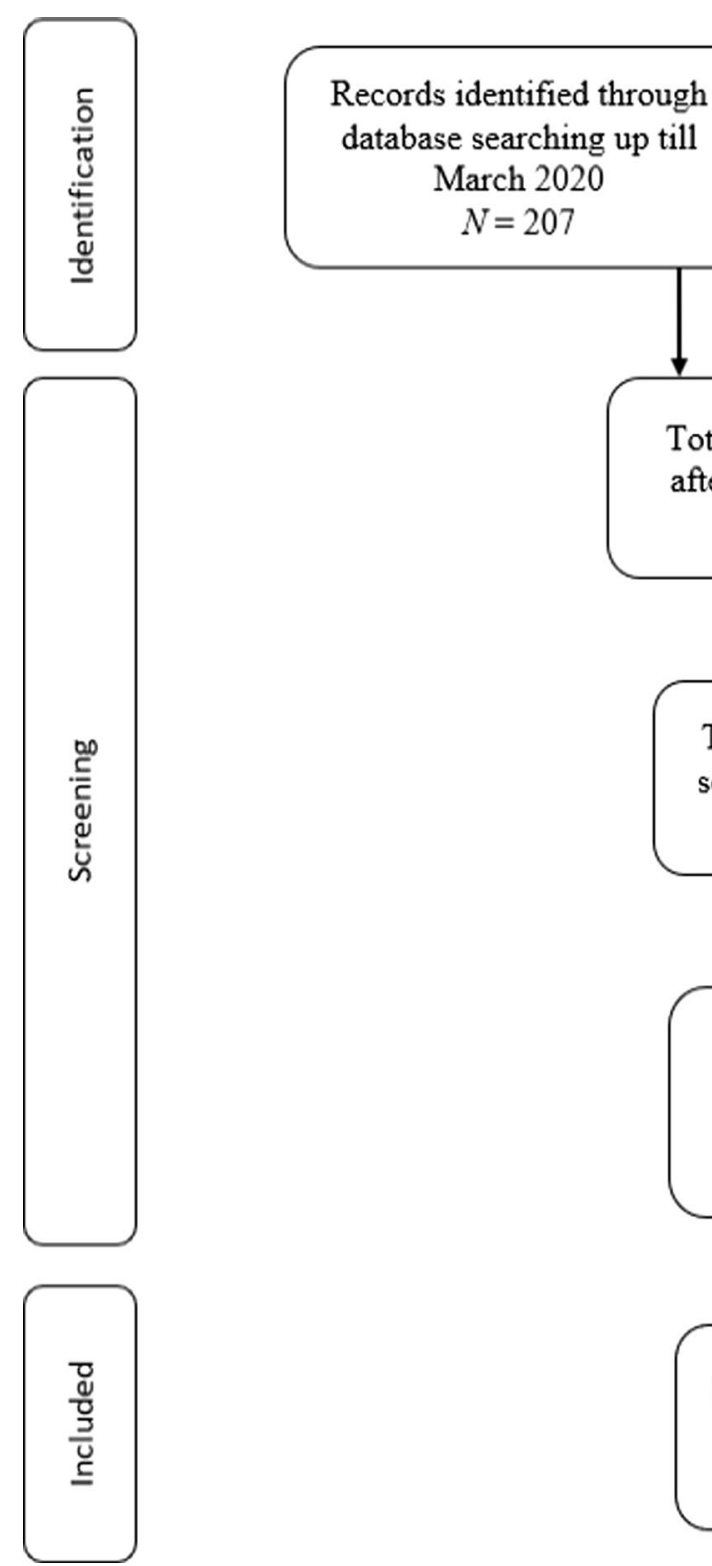

Total number of citations after duplicates removed $\mathrm{N}=199$

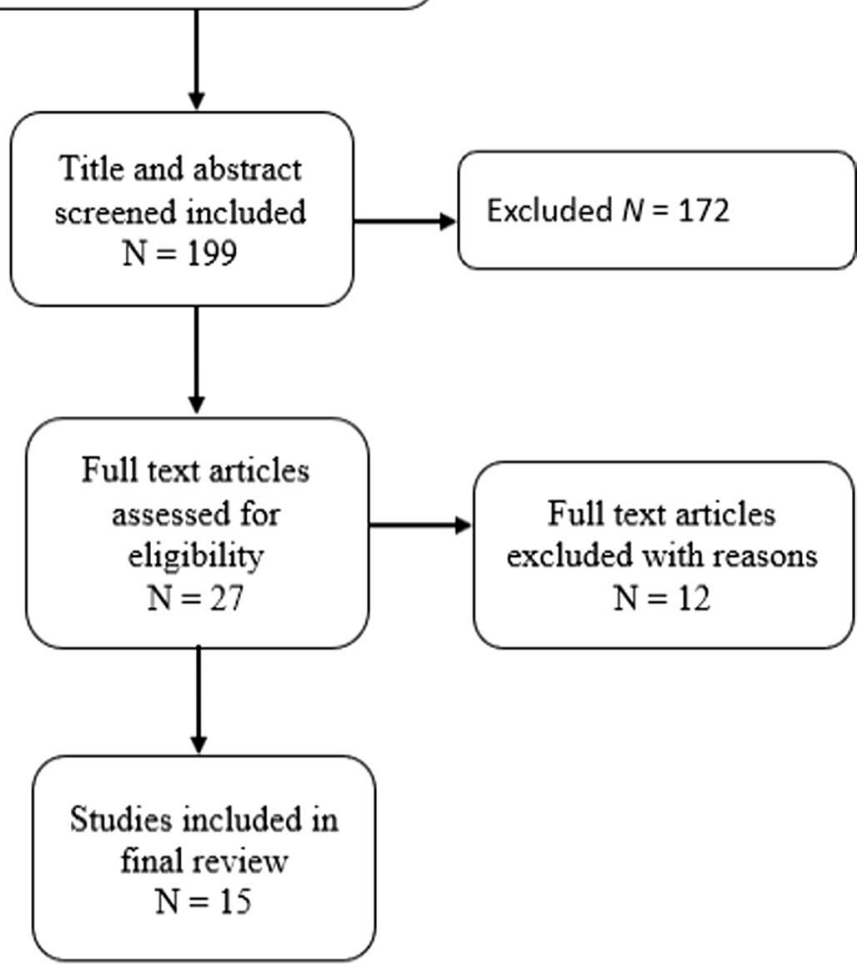

Fig. 1 Flow diagram for the search process 
Furthermore, the total sample size for all studies was $(n=19,017)$ with an age range of $5-75$ years.

\section{Study characteristics}

The majority of the studies were conducted within urban settings in the following locations: Benghazi city $(n=3)$, Sebha city $(n=3)$ and Tripoli city $(n=2)$. There were $(n=10)$ papers that discussed CMD prevalence, while $(n=8)$ provided information on the associated psychosocial risk factors on mental health. There were $(n=2)$ papers that discussed maternal wellbeing, with $(n=1)$ assessing the relationship between anaemia in pregnant women and mental health during pregnancy.

There were $(n=2)$ papers that met the initial screening criteria, however, did not meet the systematic review inclusion criteria. A cross-sectional study by Nieporent and colleagues [19] investigated the relationship between harsh environmental factors, such as living in the Sahara desert and developing a mental health condition. However, we excluded this study as it only included United State of America army personnel who were stationed in Libya and came from a different cultural and social background. In addition, Stanford and colleagues [20] conducted a feasibility study on the efficacy of a 10-week peer-led group-based recovery intervention for posttraumatic stress disorder (PTSD) due to war-related trauma. This paper primarily targeted the likelihood of completing the intervention successfully rather than focusing on using a valid clinical diagnostic tool to identify psychiatric prevalence or associated risk factors.

\section{Methodological quality of included studies}

Due to the lack of papers identified as part of the search with varying primary outcome measures, we did not conduct a formal assessment of the methodological assessment of quality. However, we have provided an overview of the methodological quality of the studies using the Mirza and colleagues [18] Checklist (see Table 1) which has been used in a similar review conducted in Iran [21]. Out of the $(n=15)$ papers, there were only three papers that gave adequate details of the methodology used. Therefore, it was challenging to accurately comment on any possible biases. Furthermore, none of the studies implemented any measure to control for selection bias and only two described their chosen group as a random sample. This also negatively affected representativeness of the data to draw a general conclusion. The Elmenfi and colleagues [22] paper was the only study that discussed and interpreted its null results in terms of its statistical significance, while all the remaining papers did not describe their null findings. There were two papers [23, 24] that did not mention or comment on the generalisability of its results to the wider population of Libya.

\section{Prevalence of CMD}

A total of $(n=3)$ papers investigated the prevalence of depression. Avasthi and colleagues [25] conducted a cross-sectional study in a psychiatric hospital at Benghazi city. The study reviewed patient care records to examine if the participant had a diagnosis of neurotic depression, based on the diagnostic criteria of the International Classification of Diseases, 9th revision (ICD-9), with overall prevalence of $58.6 \%$ depression reported by Avasthi and colleagues [25]. El Gatit and colleagues [24] also investigated the prevalence of depression in patients undergoing anticoagulation therapy for cardiac valve replacement. The study was conducted in Misurata city and focused on depression associated with chronic disease and evaluated the impact of depression on treatment adherence. El Gatit and colleagues [24] used a self-report questionnaire in a sample of $(n=62)$ cardiac patients to determine depressive symptoms, with the prevalence of depression being reported as 35.5\%. Finally, Alansari [26] conducted a study in Sebha city, using the Beck Depression Inventory in undergraduate university students, reporting a mean score (SD) for depression of 22.7 $( \pm 12.6)$. All three papers were cross sectional studies but used varied depression assessment tools which ranged from diagnostic criteria such as ICD-9 or Beck Depression Inventory to brief screening instruments such as Center for Epidemiologic Studies Depression Scale (CESD). Table 2 provides data on the estimated prevalence of anxiety and depressive disorders in the included studies.

There were a number of studies which examined both anxiety and depression $(n=6)$ within a specified population in Libya. These studies were completed in differing samples, including undergraduate university students $(n=3)$, dental patients $(n=1)$, paediatric dermatology $(n=1)$ and maternal and obstetrics $(n=1)$. The studies conducted by Salam and colleagues [27], El Ansari and colleagues [28] and Khalil [29] investigated the relationship between mental wellbeing in undergraduate students and analysed a range of associated variables, such as general health status, socio-demographics and health behaviours, respectively. The studies all used a cross-sectional study design, including outcome measures, such as the EuroQoL (EQ-5D) and Self-rated Health Questionnaire to estimate the prevalence of depression and anxiety $[28,29]$. Therefore, it was not possible to use the data from these studies to provide exact figures of CMD in the youth population at university level. However, the study by Al-Okali, and colleagues [30] investigated participants from a younger age group (6-14 years) and used a validated tool, the standardized Arabic version of the Children Depression Inventory to explore the correlation between common dermatological conditions in children and likelihood of developing anxiety or depression. The 


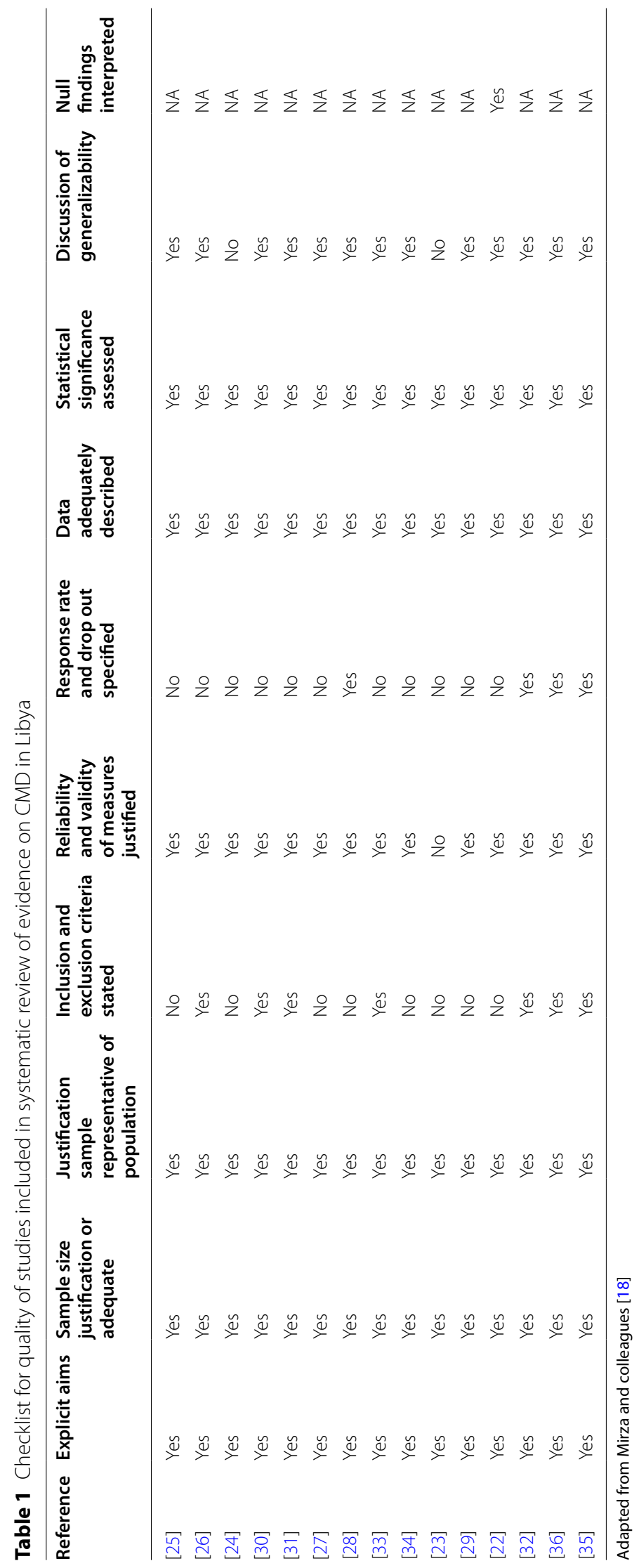




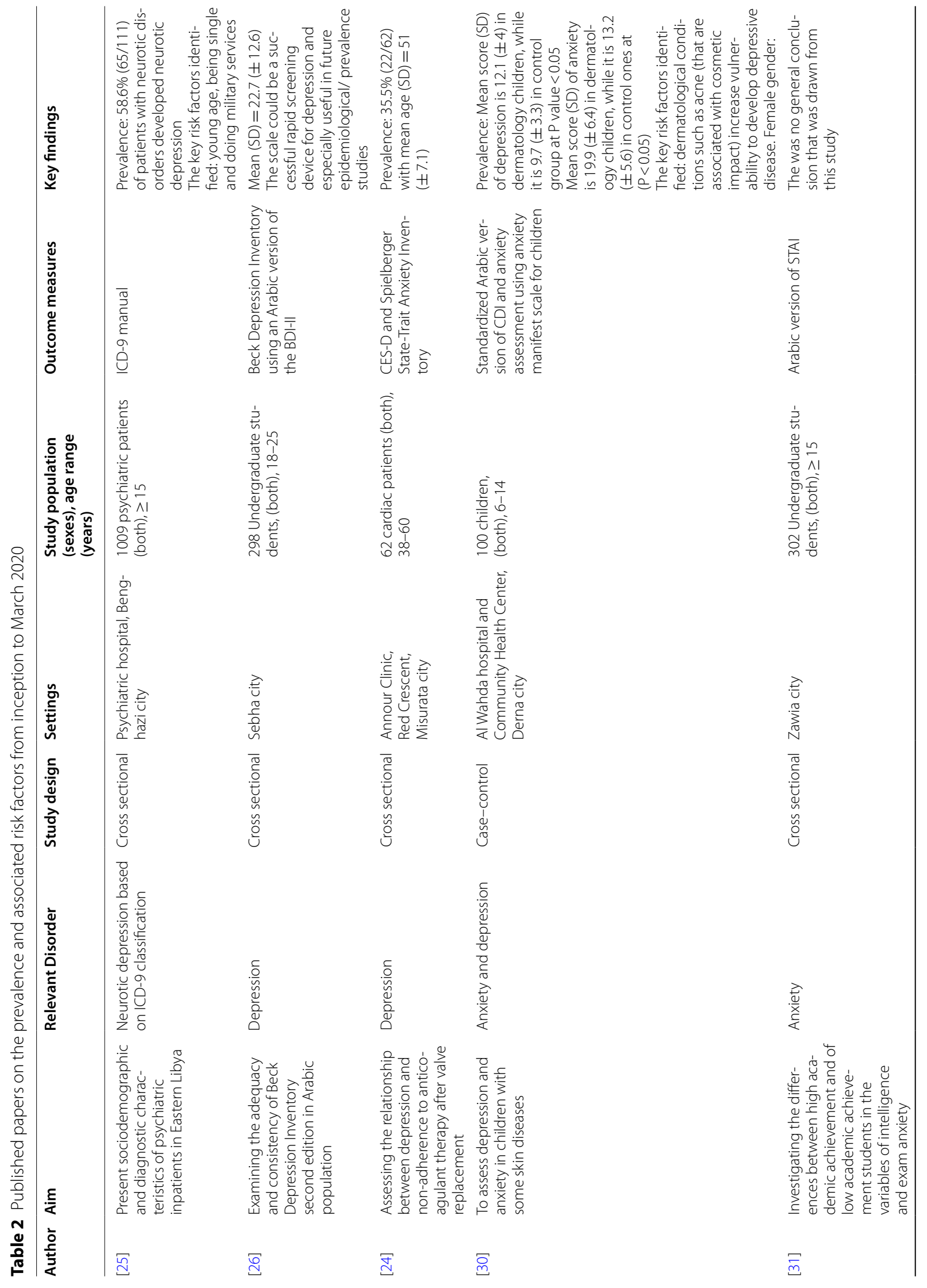




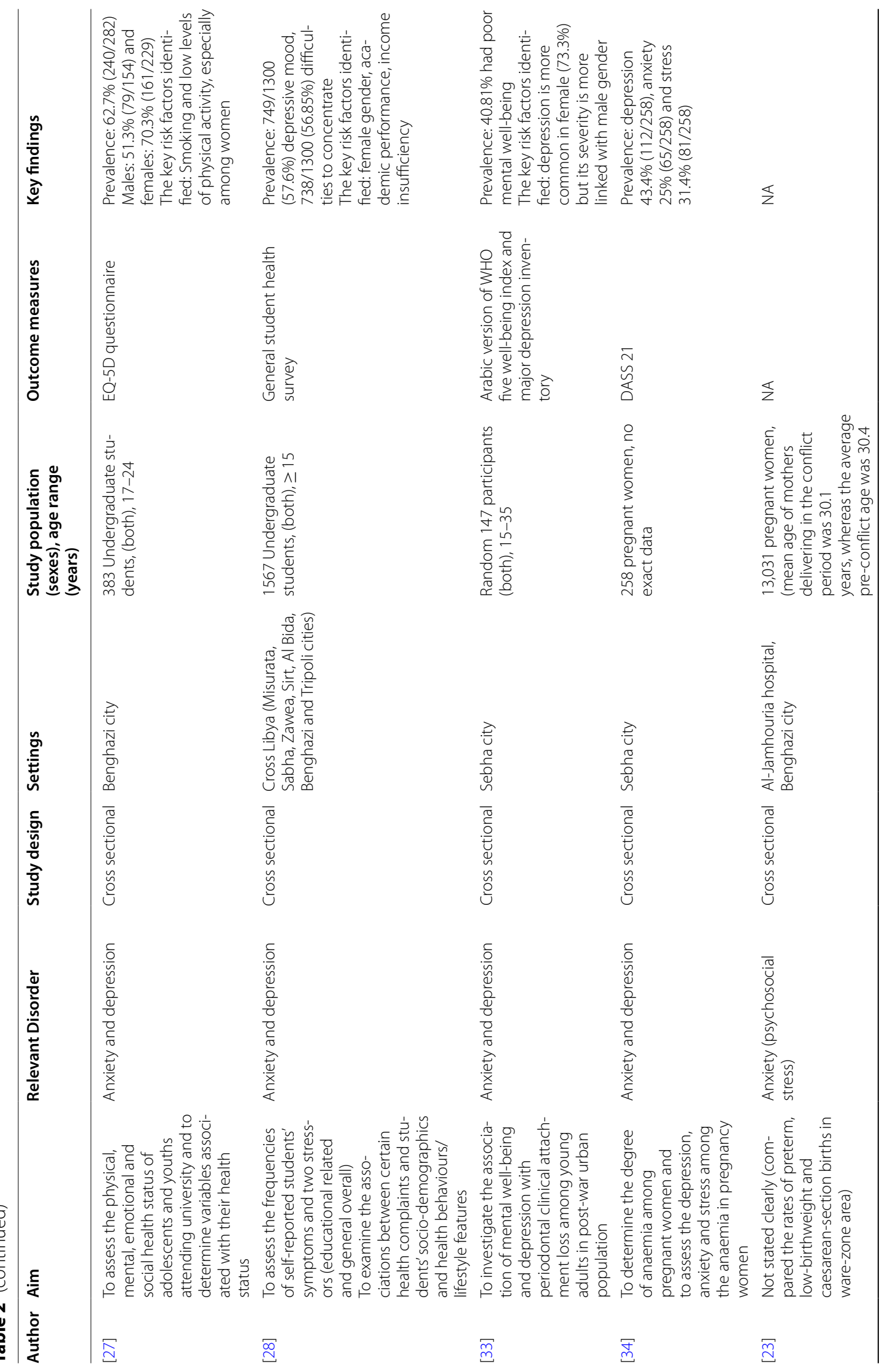




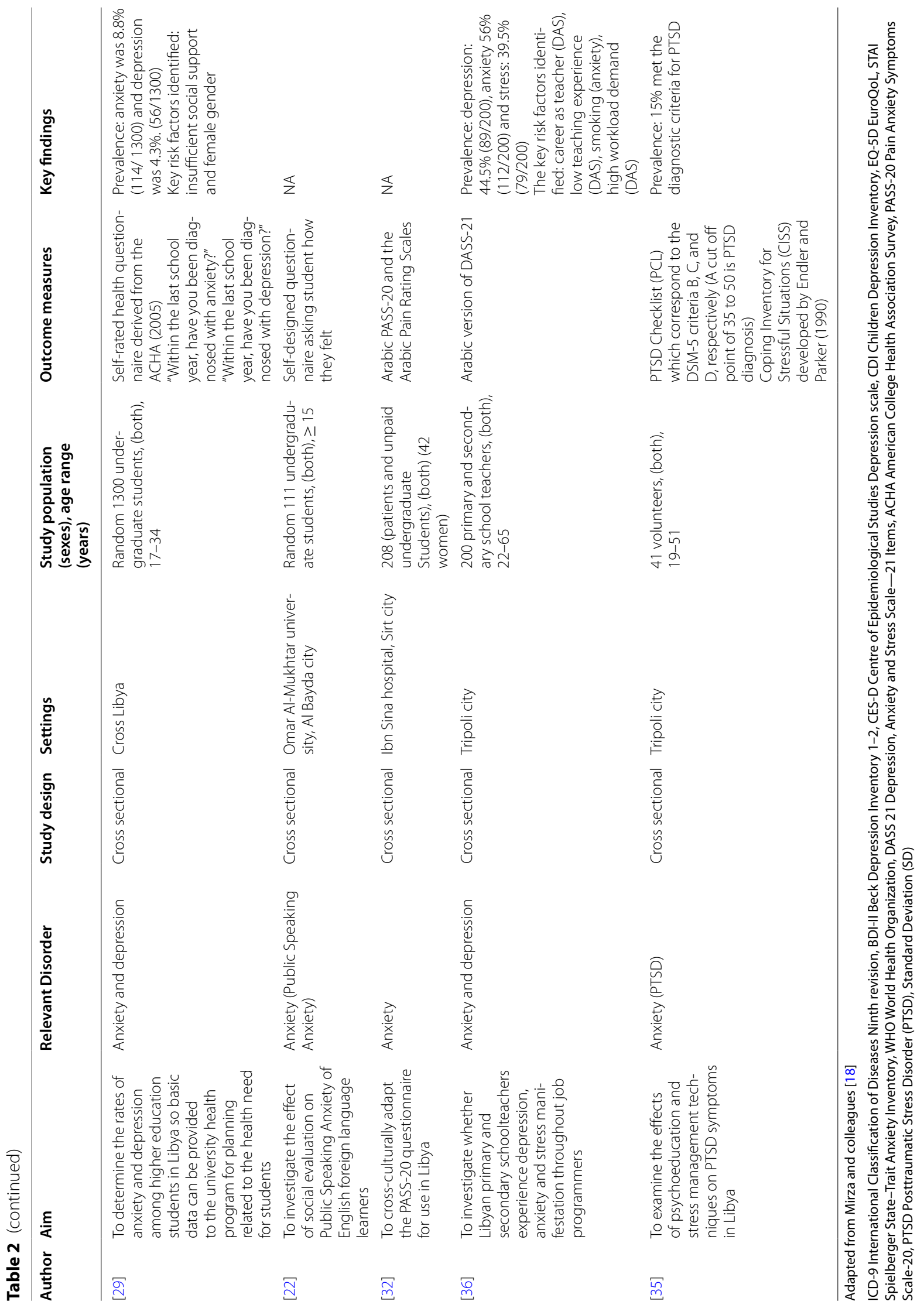


outcomes of this paper were reported as a mean score (SD) for depression of $12.1( \pm 4)$ in children with skin disease, while the mean score (SD) was $9.7( \pm 3.3)$ in the control group $(P<0.05)$.

\section{Undergraduate education and mental health}

A total of $(n=7)$ studies [22, 26-29, 31, 32] used crosssectional design and explored different presentations of CMD in undergraduate students. However, only $(n=3)$ of these studies focused on anxiety alone and tried to analyse its impact on students. The first one was Almazghoob [31] study which investigated stress on academic achievement, while Elmenfi and colleagues [22] looked at the relationship between the performance of English foreign language learners and anxiety. The final one by Tashani and colleagues [32] was cross-cultural study that investigated the Pain Anxiety Symptoms Scale-20 (PASS20) questionnaire in sample of Libyan students.

\section{Oral health and mental disorders}

One of the included studies examined mental health in a dental clinic in Sebha city [33]. This study was conducted on a random sample of 147 individuals within an urban setting in post-war Libya and investigated the mental well-being of a periodontal clinical population. A total of $40.8 \%$ of participants reported poor mental well-being using the Arabic versions of the World Health Organization (WHO) five-item well-being index and Major Depression Inventory.

\section{Maternal Mental Health}

Jiji and colleagues [34] and Bodalal and colleagues [23] looked at the association between anaemia in pregnancy and mental health, while the second paper explored the correlation between traumatic stress from living in a war-zone area and rates of preterm, low-birthweight and caesarean-section births. Unlike, Bodalal and colleagues [23] study which lacked the use of a validated psychological tool to diagnose anxiety or depression, the Jiji and colleagues [34] study used the DASS 21 survey which allowed for an estimation of the prevalence of anxiety and depression. The results of the study found no significant difference in terms of correlation between CMD (depression $43.4 \%$ and anxiety $25 \%$ ) and developing anaemia.

\section{War trauma and PTSD}

The only paper which investigated an anxiety-related disorder in association with ongoing war in Libya was conducted by Mughairbi and colleagues [35]. The study aimed at assessing the effectiveness of psychoeducation and stress management techniques on PTSD symptoms. The study involved a sample of $(n=41)$ volunteers from the capital Tripoli and assessed each participants exposure to the February 2011 events. A total of $15 \%$ of the sample were reported as experiencing PTSD based on the Diagnostic and Statistical Manual of Mental Disorders (DSM-5) criteria Mughairbi and colleagues [35].

\section{Risk factors}

Factors such as the female gender was reported as a potential risk factor for CMD in the Libyan population. This was evident in El Ansari and colleagues [28] and Khalil [29] studies which were conducted in undergraduate students from different Libyan institutions and cities. The studies showed a significant positive association between CMD and being a female student. Al-Okali, and colleagues [30] study reported a higher level of poor mental health among Libyan women in comparison to men even though the gender difference in this paper did not reach a statistical significance. There were few explanations why being a woman could increase your risk of CMD. Khalil [29] stated females were more likely to struggle with an increased pressure especially from their study so they are less able to cope well, while AlOkali, and colleagues [30] study stated that dermatological conditions such as psoriasis are associated with social stigma and make females more sensitive in self-esteem. On the other hand, the Avasthi and colleagues [25] study found an association between male gender and developing depressive symptoms which was attributed to the high proportion of men who represented the majority of patients in an inpatient psychiatric unit. Furthermore, it was outlined it was more culturally acceptable for Libyan women to seek traditional healers.

The other risk factor that was associated with CMD in Libya was cigarette smoking. Tobacco was found to be a significant predictor of mental ill-health among Libyan men [36]. Out of the 200 secondary school teachers in Tripoli who were involved in the study, $18.5 \%$ of them reported cigarette smoking. Participants in the study who smoked were significantly more likely to experience a higher level of anxiety compared with non-smokers [36]. Similarly, the Salam and colleagues [27] study conducted in undergraduate students at the University of Benghazi reported $17.2 \%$ of the participants were cigarette smokers. However, Salam and colleagues [27] did not report any significant association with poor mental health status and smoking. Both $\mathrm{El}$ ansari and colleagues [28] and Salam and colleagues [27] highlighted that unlike alcohol consumption and drug misuse, smoking was socially acceptable in Libyan society especially for males [27, 28].

Certain occupations, especially those that require high work demand such as teaching and military service were linked to an increased risk of developing CMD [25, 36]. The later study showed teachers in the Tripoli educational area were experiencing high levels of depression, 
stress, and anxiety. In addition, they were also more likely to use negative coping mechanisms, such as excess tea/coffee consumption and smoking. In addition, the Avasthi and colleagues [25] study, reported that working in the Libyan Army was one of the strongest risk factors (37\%) for developing neurotic disorders, such as depression in comparison to students $(6 \%)$ or individuals who were unemployed (6\%). Mental health and economic circumstances were strongly interconnected, with El Ansari and colleagues [28] reporting a significant association between income insufficiency especially for students who financially support themselves during university and poor mental health. Moreover, the study by El Ansari and colleagues [28] found students who have high academic expectations are more likely to experience CMD.

\section{Discussion}

The aim of the systematic review was to conduct a synthesis of evidence regarding the prevalence and associated risk factors of CMD in Libya. The main findings of the systematic review were the prevalence of CMD which ranged from 4.3 to $58.6 \%$ for depression and $8.8-56 \%$ for anxiety. However, the results need to be interpreted with caution due to the paucity of robust epidemiological research related to psychiatric morbidity in Libya [12]. This systematic review is the first to investigate the prevalence of CMD in Libya, a Middle East and North African (MENA) nation which has suffered from ongoing conflict and political unrest since February 2011 [37]. It was also noticeable that most of the research was conducted in Urban settings across three major cities in Libya; Benghazi $[23,25,27]$, Sebha city $[26,33,34]$ and Tripoli [35, 36 ] which could be due to lack of mental health service provision within rural settings.

The included papers consisted of a variety of outcome measures for CMD from basic socio-economic data to diagnostic tools for CMD [24, 26, 30]. Several depression assessment tools were used ranging from gold standard measures, such as ICD-9 [25], a self-report measure of depressive symptoms [Center for Epidemiologic Studies Depression Scale, (CES-D)] [24] and the Beck Depression Inventory [26]. The last study by Alansari [26] utilised a validated measure of depression in the Arabic language which made it linguistically and culturally appropriate for investigating CMD within this population [38].

From the results, it is evident that maternal mental and physical health has been affected by Libya's war-zone status [23, 34]. PTSD was found to be correlated with preterm, low-birthweight and caesarean-section births [23]. However, in terms of CMD and physical health conditions there was no correlation found between the prevalence of CMD and anaemia in the Jiji and colleagues [34] study. One of the studies examined the mental health of dental patients and concluded that $40.8 \%$ had poor mental wellbeing [33].

There are an increasing number of young people who are going to university as completing a university education has become an important factor for employment and financial independence [39]. As a result, there is more fund for improving student's wellbeing at university and more interest in developing student's mental health for better academic performance. This was evident on this systematic review as seven out of the fifteen studies were conduct on undergraduate students.

The results of the systematic review suggest that the associated risk factors for CMD have potentially been influenced by political unrest and Libya's war-zone status [5]. Unfortunately, Libya has been involved in many different military conflicts, such as the Egypt-Libya war (1977), Chadian-Libyan conflict (1978-1987), United Nation Sanctions on Libya (1992-1999) and the ongoing Libyan Civil (2011-present). In addition, the significant political unrest has decreased opportunities for the development of mental health service provision and policy initiatives.

The common reported risk factors found in systematic review were smoking, low health awareness, poor socioeconomic status and female gender. The significance of sex has also described in other systematic reviews, such as Abdul Razzak and colleagues [40] which was conducted in United Arab Emirates (UAE) and Bener and colleagues [41] which was conducted in Qatar, which also found female sex as a common contributing factors for poor mental health. It is worth mentioning that most studies analysed both depression and anxiety as combined a condition for poor mental health and the associated risk factors were not thoroughly analysed by most of the studies and did not follow a particular pattern.

\section{Strengths and limitations}

Despite the limited availability of prevalence data on CMD within Libya, $(n=10)$ of the included studies were conducted in the Arabic language [23, 24, 26, 29-33, 35, 36 ensuring that the measures used were culturally and linguistically appropriate for the target population. Previous research using validated outcome measures has shown the importance of culturally sensitive language tests when conducting research in non-English speaking countries [42]. The majority of research in mental health is conducted in the west. Therefore, robust methods of culturally validating instruments for the Libyan population is needed. Despite years of turmoil in Libya there were only a handful of studies on mental health that provided limited evidence on the mental health morbidity in this population. The study strengths include a synthesis of the existing data on CMD in Libya and associated risk 
factors. The limited resource availability is an issue that should be tackled [12]. Particularly there is little evidence on psychological interventions and research should be carried out in this area which may help in reducing the huge mental health treatment gap.

\section{Mental Health Research in Libya: the way forward}

The results of the systematic review highlight the limited availability of mental health research in Libya. The issue of high psychiatric morbidity is not only in Libya but across the Arab world [16]. The importance of mental health is now being acknowledged; however, appropriate mental health system research, robust mental health epidemiological data and intervention research are urgently needed. The present systematic review has provided an important means of synthesising the available evidence for CMD in Libya, contributing to the evidence base for the prevalence of mental health disorders in a MENA population. An important consideration is that the current pandemic may have led to a rise on mental health problems [43], due to bereavement of loved ones or selfisolation and feelings of loneliness [44]. We consider it will be important to include patients and the public in discussions around improving mental health care through a service-lead care approach in which patient's user lead care approach in which patients' feedback influences the development and strengthening of the healthcare system.

\section{Conclusions}

Mental health is yet to be acknowledged in Libya as a key priority area for research. Understanding the epidemiological basis of mental health disorders can have important implications for the development of mental health services in Libya. Research should focus on the development of culturally sensitive mental health services and the timely translation of research findings into policy and legislative initiatives to support those with mental health difficulties in Libya.

\begin{abstract}
Abbreviations
CES-D: Center for Epidemiologic Studies Depression Scale; CMD: Common Mental Disorders; DASS: Depression Anxiety Stress Scale; EQ-5D: EuroQoL Questionnaire; LMICs: Low- and Middle-Income Countries; IDRAAC: Institute for Development, Research, Advocacy and Applied Care; ICD-9: International Classification of Diseases, 9th revision; MENA: Middle East and North Africa; NICE: National Institute for Health and Care Excellence ; PASS-20: Pain Anxiety Symptoms Scale-20; SD: Standard deviation; WHO: World Health Organization.
\end{abstract}

\section{Supplementary Information}

The online version contains supplementary material available at https://doi. org/10.1186/s41983-021-00408-y.

Additional file 1. Search strategy.

\section{Acknowledgements}

Nil.

\section{Authors' contributions}

MA played a key role in the conception, design of the study, collecting the data, previous literature review, researches regarding this topic and is a key contributor in writing the manuscript. AR was the first person who had an idea about the topic of this systematic review, contributed to structuring the method section and follow-up the writing process. NG is a major contributor in writing the manuscript and the design of the study. AA wrote the introduction section and helped with structuring the references. UA sorted out the data search and ensured the replication of the results. $\mathrm{NH}$ provided feedback on the writing process of the manuscript. All authors read and approved the final manuscript.

Funding

No funding received.

\section{Availability of data and materials}

PubMed, Medline, EMBASE, PsychINFO, CINHAL, and the Institute for Development, Research, Advocacy and Applied Care (IDRAAC).

\section{Declarations}

Ethics approval and consent to participate

Not applicable.

\section{Consent for publication}

Not applicable.

\section{Competing interests}

The authors declare that they have no competing interests.

\section{Author details}

${ }^{1}$ Singleton Hospital, Sketty Ln, Sketty, Swansea SA2 8QA, UK. ${ }^{2}$ Lancashire and South Cumbria NHS Foundation Trust, Preston PR5 6AW, UK. ${ }^{3}$ University of Central Lancashire, Preston PR1 2HE, UK. ${ }^{4}$ Pakistan Institution of Living and Learning, Karachi, Pakistan. ${ }^{5}$ Research Global Mental Health, Division of Psychology and Mental Health, Lead Culture and International Mental Health Research Group, University of Manchester, Lancashire Care NHS Foundation Trust, Preston PR5 6AW, UK.

Received: 11 February 2021 Accepted: 29 October 2021

Published online: 03 December 2021

\section{References}

1. Ali G, Ryan G, De Silva M. Validated screening tools for common mental disorders in low- and middle-income countries: a systematic review. PLoS ONE. 2016;11(6): e0156939. https://doi.org/10.1371/journal.pone.01569 39

2. Steel Z, Marnane C, Iranpour C, Chey T, Jackson JW, Patel V, et al. The global prevalence of common mental disorders: a systematic review and meta-analysis 1980-2013. Int J Epidemiol. 2014;43(2):476-93. https://doi. org/10.1093/ije/dyu038.

3. Wainberg ML, Scorza P, Shultz JM, Helpman L, Mootz JJ, Johnson KA, et al. Challenges and opportunities in global mental health: a research-topractice perspective. Curr Psychiatry Rep. 2017;19(5):28. https://doi.org/ 10.1007/s11920-017-0780-z.

4. Elachi NE, Papamichail A, Rizk A, Lindsay H, Menassa M, Abdul-Khalek RA, et al. A conceptual framework for capacity strengthening of health research in conflict: the case of the Middle East and North Africa region. Global Health. 2019. https://doi.org/10.1186/s12992-019-0525-3.

5. Charlson F, Steel Z, Degenhardt L, Chey T, Silove D, Marnane C, et al. Predicting the impact of the 2011 conflict in Libya on Population Mental Health: PTSD and depression prevalence and mental health service requirements. PLoS ONE. 2012;7(7): e40593. https://doi.org/10.1371/journ al.pone.0040593. 
6. Collins P, Patel V, Joestl S, March D, Insel T, Daar A, et al. Grand challenges in global mental health. Nature. 2011;475(7354):27-30. https:// doi.org/10.1038/475027a.

7. De Silva M, Cooper S, Li H, Lund C, Patel V. Effect of psychosocial interventions on social functioning in depression and schizophrenia: meta-analysis. Br J Psychiatry. 2013;202(4):253-60. https://doi.org/10. 1192/bjp.bp.112.118018.

8. Ferrari AJ, Charlson FJ, Norman RE, Patten SB, Freedman G, Murray CJ, et al. Burden of depressive disorders by country, sex, age, and year: findings from the global burden of disease study 2010. PLoS Med. 2013. https://doi.org/10.1371/journal.pmed.1001547.

9. Walker ER, McGee RE, Druss BG. Mortality in mental disorders and global disease burden implications: a systematic review and metaanalysis. JAMA Psychiat. 2015;72(4):334-41. https://doi.org/10.1001/ jamapsychiatry.2014.2502.

10. Wang J, Wu X, Lai W, Long E, Zhang X, Li W, et al. Prevalence of depression and depressive symptoms among outpatients: a systematic review and meta-analysis. BMJ Open. 2017;7(8): e017173. https://doi. org/10.1136/bmjopen-2017-017173.

11. McManus S, Bebbington PE, Jenkins R, Brugha T. Mental Health and Wellbeing in England: the Adult Psychiatric Morbidity Survey 2014. NHS digital; 2016

12. Rhouma AH, Husain N, Gire N, Chaudhry IB. Mental health services in Libya. BJPsych Int. 2016;13(3):70-1 (PMID: 29093908).

13 Hassanzadeh A, Heidari Z, Feizi A, Keshteli AH, Roohafza H, Afshar H, et al. Association of stressful life events with psychological problems: a large-scale community-based study using grouped outcomes latent factor regression with latent predictors. Comput Math Methods Med. 2017. https://doi.org/10.1155/2017/3457103.

14. Heim C, Shugart M, Craighead WE, Nemeroff CB. Neurobiological and psychiatric consequences of child abuse and neglect. Dev Psychobiol. 2010;52(7):671-90. https://doi.org/10.1002/dev.20494.

15. Patel V, Chisholm D, Dua T, Laxminarayan R, Medina-Mora MA, editors, Disease control priorities, (Volume 4): mental, neurological, and substance use disorders. The World Bank; 2016. https://doi.org/10.1596/ 978-1-4648-0426-7.

16. Okasha A, Karam E, Okasha T. Mental health services in the Arab world. World Psychiatry. 2012;11(1):52-4. https://doi.org/10.1016/j.wpsyc. 2012.01.008.

17. Lund C, Breen A, Flisher AJ, Kakuma R, Corrigall J, Joska JA, et al. Poverty and common mental disorders in low- and middle-income countries: a systematic review. Soc Sci Med. 2010;71(3):517-28. https:// doi.org/10.1016/j.socscimed.2010.04.027.

18. Mirza I, Jenkins R. Risk factors, prevalence, and treatment of anxiety and depressive disorders in Pakistan: systematic review. BMJ. 2004;328(7443):794. https://doi.org/10.1136/bmj.328.7443.794.

19. Nieporent HJ. Adaptation to living and working in the desert: a psychiatric survey among United States army personnel in the Libyan Sahara. Mil Med. 1963;128(10):1016-23. https://doi.org/10.1093/milmed/128. 10.1016.

20. Stanford MS, Elverson TM, Padilla Jl, Rogers EB. Feasibility and efficacy of a peer-led recovery group program for war-related trauma in Libya. S Afr J Psychol. 2013:44(1):97-105. https://doi.org/10.1177/0081246313 515847.

21 Alipour Z, Kheirabadi G, Kazemi A, Fooladi M. The most important risk factors affecting mental health during pregnancy: a systematic review. East Mediterr Health J. 2018;24(6):549-59. https://doi.org/10.26719/ 2018.24.6.549.

22. Elmenfi F, Gaibani A. The role of social evaluation in influencing public speaking anxiety of English language learners at Omar Al-Mukhtar University. Arab World English Journal. 2016;7(3):496-505.

23. Bodalal Z, Agnaeber K, Nagelkerke N, Stirling B, Temmerman M, Degomme O. Pregnancy outcomes in Benghazi, Libya, before and during the armed conflict in 2011. East Mediterr Health J. 2014;20(3):17580. https://doi.org/10.26719/2014.20.3.175

24. El Gatit AM, Haw M. Relationship between depression and non-adherence to anticoagulant therapy after valve replacement. East Mediterr Health J. 2003;9(1-2):12-9.

25. Avasthi A, Khan M, Elroey A. Inpatient sociodemographic and diagnostic study from a psychiatric hospital in Libya. Int J Soc Psychiatry. 1991;37(4):267-79. https://doi.org/10.1177/002076409103700406.
26. Alansari B. Internal consistency of an Arabic adaptation of the beck depression inventory-II with college students in eighteen Arab countries. Soc Behav Personal Int J. 2006;34(4):425-30. https://doi.org/10. 2224/sbp.2006.34.4.425.

27 Salam AA, Alshekteria AA, Mohammed HA, Al Abar NM, Al Jhany MM, Al Flah MF. Physical, mental, emotional and social health status of adolescents and youths in Benghazi, Libya. East Mediterr Health J. 2012;18(6):586-97. https://doi.org/10.26719/2012.18.6.586.

28. El Ansari WE, Khalil K, Stock C. Symptoms and health complaints and their association with perceived stressors among students at nine Libyan universities. Int J Environ Res Public Health. 2014;11(12):12088107. https://doi.org/10.3390/ijerph111212088.

29. Khalil KA. Rates of anxiety and depression among higher education students In Libya-2015. ISBN: 978-605-64453-2-3.

30 Al-Okali M, Ei-Shourbagy O, Wassif S. Psychiatric morbidity (depression and anxiety) in children with some dermatological diseases at Derna Libya. Zagazig J Occup Health Safety. 2009. https://doi.org/10.4314/ zjohs.v1i2.45886.

31. Almazghoob IS. 3. The difference in Intelligence and exam anxiety between high and low achieving students at the 7th of April university, Libya. Int J Talent Dev. 2011. https://sp.ust.edu/ojs/index.php/AJTD/ article/view/668 Accessed 20th February 2021.

32. Tashani OA, AlAbas OA, Kabil RA, Johnson MI. Psychometric properties of an Arabic pain anxiety symptoms Scale-20 (PASS-20) in healthy volunteers and patients attending a physiotherapy clinic. Int J Behav Med. 2017;24(3):457-72. https://doi.org/10.1007/s12529-016-9608-1.

33. Peeran SW, Kumar NP, Azaruk FA, Alsaid FM, Abdalla KA, Mugrabi MH, et al. Association between mental well-being, depression, and periodontal attachment level among young adults of the postwar Sebha city, Libya: a pilot study. J Nat Sci Biol Med. 2014;5(2):308. https://doi. org/10.4103/0976-9668.136172.

34. Jiji DB, Rajagopal K. Assessment of depression anxiety and stress among the anaemia in pregnant women attending selected health care facilities in Sebha, Libya. Asian Pac J Health Sci. 2014;1 (4):438-42. https://doi.org/10.21276/apjhs.2014.1.4.21.

35. Mughairbi FA, AbdulazizAlnajjar A, Hamid A. Effects of psychoeducation and stress coping techniques on posttraumatic stress disorder symptoms. Psychol Rep. 2020;123(3):710-24. https://doi.org/10.1177/ 0033294118825101.

36. Taher YA, Samud AM, Hashemi MM, Kabuoli NF. Prevalence of depression, anxiety and stress among Libyan primary and secondary schoolteachers: a cross-sectional study. J Pharm Sci. 2016;403(3972):1-2. https://doi.org/10.12816/0033311.

37. Farag AA. The role of social supports and copying strategies in mediating the impact of civil war on Libyan Children's Mental Health (Doctoral dissertation, University of Leicester). 2020. https://doi.org/10. 25392/leicester.data.12652325.v1.

38. Farhood LF, Dimassi H. Validation of an Arabic Version of the GHQ-28 against the beck depression inventory for screening for depression in war-exposed civilians. Psychol Rep. 2015;116(2):470-84.

39. Bania E, Kvernmo S. Tertiary education and its association with mental health indicators and educational factors among Arctic young adults: the NAAHS cohort study. Int J Circumpolar Health. 2016;75(1):32086. https://doi.org/10.3402/ijch.v75.32086.

40. Abdul Razzak H, Harbi A, Ahli S. Depression: prevalence and associated risk factors in the United Arab Emirates. Oman Med J. 2019;34(4):27482. https://doi.org/10.5001/omj.2019.56.

41. Bener A, Ghuloum S, Abou-Saleh M. Prevalence, symptom patterns and comorbidity of anxiety and depressive disorders in primary care in Qatar. Soc Psychiatry Psychiatr Epidemiol. 2011;47(3):439-46. https:// doi.org/10.1007/s00127-011-0349-9.

42. Snodgrass JG, Lacy MG, Upadhyay C. Developing culturally sensitive affect scales for global mental health research and practice: emotional balance, not named syndromes, in Indian Adivasi subjective wellbeing. Soc Sci Med. 2017;1(187):174-83. https://doi.org/10.1016/j.socsc imed.2017.06.037.

43 Fiorillo A, Gorwood P. The consequences of the COVID-19 pandemic on mental health and implications for clinical practice. Eur Psychiatry. 2020. https://doi.org/10.1192/j.eurpsy.2020.35. 
44. Hill RM, Kaplow JB, Oosterhoff B, Layne CM. Understanding grief reactions, thwarted belongingness, and suicide ideation in bereaved adolescents: toward a unifying theory. J Clin Psychol. 2019;75(4):780-93.

\section{Publisher's Note}

Springer Nature remains neutral with regard to jurisdictional claims in published maps and institutional affiliations.

\section{Submit your manuscript to a SpringerOpen ${ }^{\circ}$ journal and benefit from:}

- Convenient online submission

- Rigorous peer review

- Open access: articles freely available online

- High visibility within the field

- Retaining the copyright to your article

Submit your next manuscript at $\mathbf{s p r i n g e r o p e n . c o m ~}$ 